\title{
Aborto em bovinos devido à intoxicação por Tetrapterys acutifolia (Malpighiaceae) ${ }^{1}$
}

\author{
Saulo A. Caldas ${ }^{2}$, Tiago C. Peixoto ${ }^{2}$, Vivian A. Nogueira ${ }^{3}$, Ticiana Nascimento França ${ }^{3}$, \\ Carlos H. Tokarnia ${ }^{4}$ e Paulo V. Peixoto ${ }^{4}$
}

\begin{abstract}
Caldas S.A., Peixoto T.C., Nogueira V.A., França, T.N., Tokarnia C.H. \& Peixoto P.V. 2011. [Abortion in cattle due to Tetrapterys acutifolia poisoning.] Aborto em bovinos devido à intoxicação por Tetrapterys acutifolia (Malpighiacae). Pesquisa Veterinária Brasileira 31(9):737-746. Projeto Sanidade Animal Embrapa/UFRRJ, Seropédica, RJ 23890-000, Brazil. E-mail: saulo-andrade@bol.com.br

Tetrapterys acutifolia Cav. (fam. Malpighiacae) stands out among the most important toxic plants of the Brazilian Southeast Region. These plants are responsible for a significant number of deaths in over 1-year-old cattle, especially in the states of Rio de Janeiro and São Paulo. This study aims to demonstrate that T. acutifolia is also able to induce abortion in cattle and to characterize the clinic-pathological alterations in cows and fetuses. Four cows, kept on pasture were used in the experiments which were performed on a farm in the county of Barra do Piraí, RJ, Brazil. The sprouts and young leaves of T. acutifolia were collected from the vicinity shortly before disposed in a trough. The experimental cows ingested the plant material at doses of $2.5 \mathrm{~g} / \mathrm{kg} /$ day (one cow), $5 \mathrm{~g} / \mathrm{kg} /$ day (two cows) and $10 \mathrm{~g} / \mathrm{kg} /$ day (one cow) until abortion occurred. All four cows aborted. The cows showed cardiac arrhythmia, muscular tremors, anorexia, ascites, distended jugular veins, edema of the sternal region and dewlap, and abortion ( 23 to 76 days after the beginning of ingestion of the plasnt) from the $5^{\text {th }}$ to the $28^{\text {th }}$ day of the experiment. Only one cow which received $10 \mathrm{~g} / \mathrm{kg} /$ day died with characteristic signs of heart failure, 36 days after she had aborted. Gross examination of the fetuses revealed hydrothorax, hydropericardium, hydroperitoneum, nutmeg appearance of the liver, few petechiae and ecchymoses in the epicardium, and pale areas in cross sections of the myocardium. The main postmortem findings in the cow that died were hydrothorax, hydropericardium and hydroperitoneum, engorged vessels at the heart base, exceedingly pale heart muscle with marked spots and stripes in cross sections. Distended jugular veins and severe edema in the sternal region and the abdominal wall were also observed. Histological examination of the fetal hearts revealed interstitial edema with incipient fibrosis and degenerative/necrotic changes of the myocytes. In the succumbed cow was found interstitial fibrosis, as well as necrotic areas and/or necrosis of individual myocytes in extensive portions of the heart, besides passive congestion of the liver. This study shows that Tetrapterys acutifolia can induce abortion in cattle and, depending on the dosage, can cause death.
\end{abstract}

INDEX TERMS: Poisonous plants, Tetrapterys acutifolia, abortion, plant poisoning, cattle.

\footnotetext{
${ }^{1}$ Recebido em 3 de novembro de 2010.

Aceito para publicação em 21 de junho de 2011.

Parte da Tese de Doutorado do primeiro autor, defendida na Universidade Federal Rural do Rio de Janeiro (UFRRJ), Seropédica, RJ 23890-000, Brasil.

${ }^{2}$ Curso de Pós-Graduação em Ciências Veterinárias, Instituto de Veterinária, UFRRJ, Seropédica, RJ. *Autor para correspondência: saulo-andrade $@$ @ol.com.br

${ }^{3}$ Departamento de Epidemiologia e Saúde Pública, Instituto de Veterinária, UFRRJ, Seropédica, RJ.

${ }^{4}$ Departamento de Nutrição Animal e Pastagem, Instituto de Zootecnia, UFRRJ, Seropédica, RJ.
}

RESUMO.- Esse estudo teve por objetivo demonstrar experimentalmente que Tetrapterys acutifolia Cav. (fam. Malpighiaceae) é capaz de provocar aborto em bovinos e caracterizar as alterações clínico-patológicas nas vacas e nos fetos. Estas plantas são responsáveis por significativo número de mortes em bovinos com mais de um ano de idade, especialmente nos Estados de Rio de Janeiro e São Paulo, mas até agora não havia sido comprovado experimentalmente seu efeito abortivo em bovinos. Os experimentos foram realizados no município de Barra do Piraí, RJ. Quatro vacas de descarte receberam brotos e folhas novas frescas de T. acutifolia, coletadas em proprieda- 
des vizinhas, nas doses de 2,5g/kg/dia, $5,0 \mathrm{~g} / \mathrm{kg} /$ dia (2 vacas) e $10 \mathrm{~g} / \mathrm{kg} / \mathrm{dia}$, até ocorrer o abortamento. 0 quadro clínico nas vacas caracterizou-se por arritmia cardíaca, tremores musculares, anorexia, ascite, jugular ingurgitada, edema de peito e barbela e aborto (23-76 dias após o início da ingestão da planta); todas as vacas abortaram. Das quatro vacas apenas uma (a que recebeu $10 \mathrm{~g} / \mathrm{kg} / \mathrm{dia}$ ) morreu 36 dias após o abortamento, com sintomas de insuficiência cardíaca. 0 exame necroscópico dos fetos/natimortos revelou hidrotórax, hidropericárdio, hidroperitônio e congestão hepática; ao corte do miocárdio, verificaram-se áreas pálidas. No exame histológico havia edema intersticial com fibrose incipiente. Na vaca que recebeu a maior dose e foi a óbito, bem como em outra intoxicada naturalmente, os achados de necropsia foram similares aos observados nos fetos, exceto pela dilatação dos vasos da base do coração e mais acentuada palidez do miocárdio. Observaram-se ainda edema subcutâneo nas regiões cervical e esternal, bem como veias jugulares ingurgitadas. Os achados histopatológicos foram necrose e edema intersticial com acentuada fibrose no miocárdio, espongiose da substância branca do encéfalo e, no fígado, congestão e leve fibrose. Adicionalmente, observou-se na vaca intoxicada espontaneamente, 17 dias após o aborto, arritmia cardíaca, jugular ingurgitada, edema de peito e barbela, anorexia com morte 43 dias após o aborto. Este estudo demonstra que Tetrapterys acutifolia é capaz de induzir aborto e, dependendo da dose, ainda causar a morte das vacas que abortarem.

TERMOS DE INDEXAÇÃO: Plantas tóxicas, Tetrapterys acutifolia, Malpighiaceae, intoxicação por planta, aborto, bovinos.

\section{INTRODUÇÃO}

A intoxicação natural por plantas do gênero Tetrapterys (fam. Malpighiaceae) cursa com insuficiência cardíaca em bovinos nos Estados de Rio de Janeiro, São Paulo, Minas Gerais (Tokarnia et al. 1989) e Mato Grosso do Sul (Carvalho et al. 2006). A intoxicação por plantas deste gênero em bovinos, foi descrita pela primeira vez em 1989, entretanto, desde 1968 nas regiões Sudeste e nordeste de Minas Gerais já havia históricos de aborto em vacas (Tokarnia et al. 1989), que não eram causados por agentes infecciosos, e vinham sendo atribuídos por fazendeiros e vaqueiros à ingestão de Rynchosia pyramidalis (cipó-correia), pelo menos em São Paulo.

A intoxicação por Tetrapterys spp. determinam quadro subagudo ou crônico de insuficiência cardíaca, usualmente em animais com mais de um ano de idade. Os principais sinais clínicos de insuficiência cardíaca congestiva, observados nesses casos, são edema subcutâneo de declive, ingurgitamento e pulsação da jugular. À necropsia verificam-se edemas cavitários, fígado com aspecto de noz-moscada, dilatação cardíaca e áreas pálidas no miocárdio. Achados histopatológicos incluem tumefação de cardiomiócitos, vacuolização de fibras, fibrose intersticial e necrose (Tokarnia et al. 1989, Tokarnia et al. 2000, Carvalho et al. 2006). Sinais clínicos neurológicos, como prostração, letargia, sonolência e debilidade são descritos em bovinos (Carvalho et al. 2006) e ovinos (Almeida et al. 2008). De acordo com Tokarnia et al. (1989), é provável que a ingestão desta planta cause aborto em bovinos.

Como medidas profiláticas só podem ser implementadas a partir de resultados que confirmem a implicação de plantas tóxicas na etiologia das enfermidades, o objetivo deste trabalho foi comprovar experimentalmente o efeito abortivo de Tetrapterys acutifolia em bovinos, além de caracterizar as alterações clínico-patológicas nas vacas e nos fetos antes e após o abortamento.

\section{MATERIAL E MÉTODOS}

\section{Animais}

Para os experimentos com Tetrapterys acutifolia Cav. (Fig.1) foram utilizadas quatro vacas mestiças em bom estado nutricional, prenhes de seis a oito meses, com 3 a 5 anos de idade, de 350-500 $\mathrm{kg}$ de peso. Adicionalmente foi acompanhado o quadro clínico de um caso natural de intoxicação por Tetrapterys multiglandulosa que resultou em aborto (Vaca 5739), no município de Valença, RJ. 0

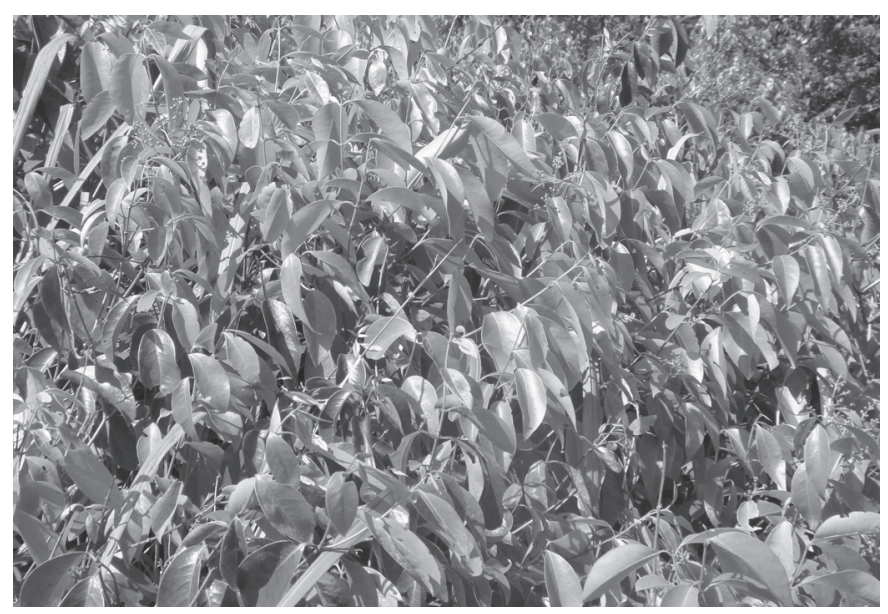

Fig.1. Brotação de Tetrapterys acutifolia, no município de Barra do Piraí, RJ.

estudo experimental foi conduzido de forma a utilizar o menor número de animais possível. Para tanto, lançamos mão dos chamados experimentos autodirecionados, ou seja, os experimentos subsequentes foram realizados a partir dos resultados obtidos no experimento-piloto; a dose inicial de $5 \mathrm{~g} / \mathrm{kg}$ de peso vivo foi escolhida com base nos estudos de Tokarnia et al. (1989).

\section{Local}

0 estudo experimental foi realizado em um sítio localizado no município de Barra do Piraí, Estado do Rio de Janeiro. Antes do início dos experimentos, os bovinos foram mantidos em piquetes com Brachiaria decumbens e, posteriormente, os animais foram alojados em baias individuais de alvenaria medindo 4,0 x 5,0m, que continham um cocho, bebedouro e cocho de sal com acesso livre.

Os exames sorológicos (ver adiante) foram realizados na Fundação de Estudo e Pesquisa em Medicina Veterinária e Zootecnia (FEP-MVZ) da UFMG e Setor de Reprodução Animal da UFRRJ.

0 processamento do material obtido das necropsias, assim como a confecção de lâminas para o exame histopatológico foram realizados no Laboratório do Setor de Anatomia Patológica, do Projeto Sanidade Animal Embrapa/UFRRJ.

\section{Procedimento experimental}

Os quatro animais foram vermifugados com ivermectina a $1 \%$ antes da cobertura e adaptados ao local por pelo menos uma semana. A fecundação das vacas foi realizada por monta natural e o diagnóstico de gestação foi confirmado por palpação retal. Antes da fecundação foram realizados exames ginecológicos e sorológicos 
para brucelose, diarréia viral bovina e rinotraqueíte infecciosa bovina (IBR), leptospirose e exames para detecção de campilobacteriose e tricomonose.

A brotação e as folhas novas de Tetrapterys acutifolia, utilizadas nos experimentos foram coletadas no município de Barra do Piraí, RJ (sítio Retiro União, propriedade vizinha ao sítio Santo Antônio, onde o experimento foi realizado) entre julho de 2007 e novembro de 2008. No experimento-piloto com a Vaca 5732 (5,0g/ $\mathrm{kg} / \mathrm{dia}$ ), a planta utilizada foi coletada entre os meses de julho e agosto de 2007; para o segundo experimento com a Vaca 5734 $(10 \mathrm{~g} / \mathrm{kg} / \mathrm{dia})$, a coleta ocorreu no mês de dezembro do mesmo ano; já para a Vaca 5735 (2,5g/kg/dia) a planta foi coletada entre os meses de março e maio de 2008 e, para a Vaca 5737 (5,0g/kg/dia), a coleta foi feita nos meses de outubro e novembro de 2008. A planta era colhida semanalmente (apenas o penúltimo e o antepenúltimo par de folhas); a dose diária (g/kg) administrada a cada animal era pesada em balança digital portátil e acondicionada em sacos plásticos individuais, que eram mantidos em geladeira a $4^{\circ} \mathrm{C}$ por no máximo uma semana. A Vaca 5732 ingeriu espontaneamente a planta fresca ofertada no cocho (Fig.2), outro animal (Vaca 5735) recebeu a planta fresca manualmente na boca; para outros dois animais (Vacas 5734 e 5737) foi necessário o fornecimento no cocho da planta triturada junto com capim Pennisetum purpureum ("capim-elefante").

A planta fresca foi administrada no cocho até o abortamento. Os bovinos foram avaliados clinicamente no início do experimento e, depois, a cada semana, com atenção especial às frequências cardíaca e respiratória, presença de edema na região esternal, ingurgitamento das jugulares, locomoção, reflexo a estímulos externos, ingestão de água e alimentos. Quando os animais começaram a demonstrar sintomas, os exames foram intensificados, e o acompanhamento clínico foi contínuo.

As necropsias foram realizadas nos fetos, logo após o abortamento e nas vacas, imediatamente após a morte. Fragmentos de coração, fígado, rins, baço, pulmões, trato gastrintestinal, pâncreas, adrenal, hipófise, tireóide, músculos esqueléticos psoas e longíssimo dorsal e sistema nervoso central foram coletados e fixados em formol a $20 \%$ e processados rotineiramente para exame histológico e corados pela hematoxilina e eosina (HE) e pelo Tricrômico Masson (coração e fígado).

Adicionalmente acompanhou-se um caso natural de intoxicação por Tetrapterys multiglandulosa, com aborto, porém tal fato não nos foi comunicado a tempo para realização da necropsia.

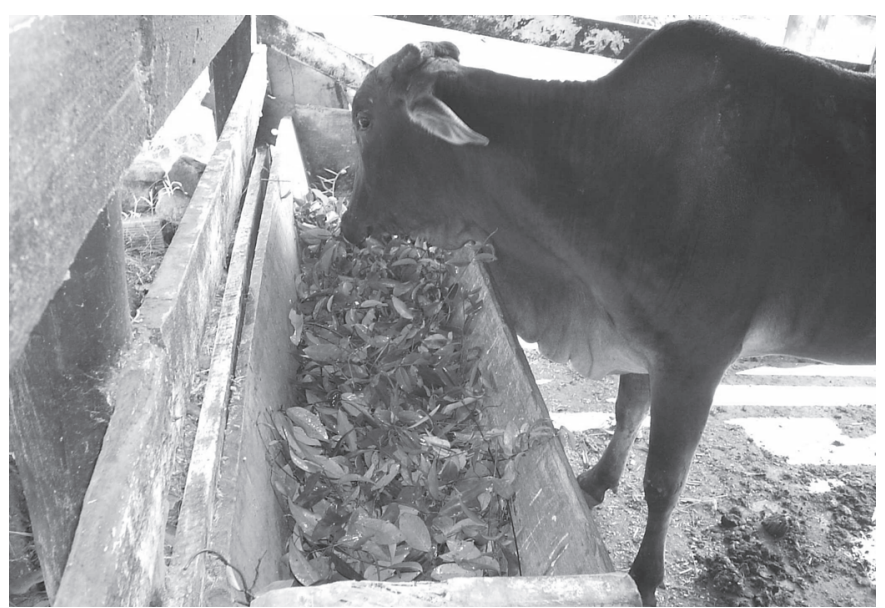

Fig.2. Bovino $5732(5,0 \mathrm{~g} / \mathrm{kg})$ ingerindo Tetrapterys acutifolia fresca diretamente no cocho.

\section{RESULTADOS}

Os principais dados sobre o delineamento experimental e o desfecho encontram-se no Quadro 1.

\section{Históricos de aborto}

Obtivemos históricos de abortos associados à ingestão de Tetrapterys spp., nos municípios de Barra do Piraí (Tetrapterys acutifolia) e, principalmente, de Valença e de Rio das Flores (Tetrapterys multiglandulosa), sobretudo no período da seca (junho-agosto). Em Barra do Piraí, dois relatos ocorreram nos anos de 1999 e 2000 em um pasto onde as vacas gestantes eram mantidas durante 15 a 20 dias antes do parto. 0 mesmo aconteceu em Valença, onde os animais eram mantidos em piquetes ou pastos poucos dias antes do parto, com exceção da Fazenda Retiro, na qual os abortos foram registrados no período de 1980 a 2002, e totalizaram pelo menos 43 casos; além disso, nesta propriedade, foi relatada a morte de uma vaca com sinais clínicos de insuficiência cardíaca. Na Fazenda do Lobo, relataram-se nove abortamentos no período de 2001 a 2008; de 1995 a 2004 ocorreram 13 casos na Fazenda Santa Fé, ambas no município de Valença. Na Fazenda dos

Quadro 1. Principais dados sobre o delineamento experimental e desfecho

\begin{tabular}{|c|c|c|c|c|c|c|c|c|}
\hline Animal & Peso & $\begin{array}{l}\text { Período de } \\
\text { gestação }\end{array}$ & $\begin{array}{l}\text { Dose } \\
\text { diária }\end{array}$ & $\begin{array}{c}\text { Quantidade da planta } \\
\text { administrada } \\
\text { diariamente }\end{array}$ & $\begin{array}{c}\text { Início dos } \\
\text { primeiros sintomas } \\
\text { após o começo } \\
\text { da administração } \\
\text { da planta }\end{array}$ & $\begin{array}{l}\text { Evolução clínica } \\
\text { até o aborto }\end{array}$ & $\begin{array}{l}\text { Prazo desde } \\
\text { o início de in- } \\
\text { gestão da planta } \\
\text { até o aborto }\end{array}$ & Desfecho \\
\hline $\begin{array}{l}\text { Vaca } \\
5732\end{array}$ & $\begin{array}{c}355 \\
\mathrm{~kg}\end{array}$ & 7,5 meses & $5,0 \mathrm{~g} / \mathrm{kg}$ & $1,775 \mathrm{~kg}$ & $21^{\circ}$ dia & 10 dias & 31 dias & $\begin{array}{l}\text { Aborto Macho } \\
\qquad(5731)\end{array}$ \\
\hline $\begin{array}{l}\text { Vaca } \\
5734\end{array}$ & $\begin{array}{c}428 \\
\mathrm{~kg}\end{array}$ & 8 meses & $10 \mathrm{~g} / \mathrm{kg}$ & $4,280 \mathrm{~kg}$ & $5^{\circ}$ dia & 18 dias & 23 dias & $\begin{array}{c}\text { Aborto Fêmea } \\
\text { (5733). A vaca } \\
\text { (5734) morreu } \\
36 \text { dias após ter } \\
\text { abortado }\end{array}$ \\
\hline $\begin{array}{l}\text { Vaca } \\
5735\end{array}$ & $\begin{array}{c}476 \\
\mathrm{~kg}\end{array}$ & $\begin{array}{l}6 \text { meses e } \\
1 \text { semana }\end{array}$ & $2,5 \mathrm{~g} / \mathrm{kg}$ & $1,190 \mathrm{~kg}$ & $29^{\circ}$ dia & 47 dias & 76 dias & $\begin{array}{c}\text { Aborto Fêma } \\
\text { (5736) }\end{array}$ \\
\hline $\begin{array}{l}\text { Vaca } \\
5737\end{array}$ & $\begin{array}{c}407 \\
\mathrm{~kg}\end{array}$ & 7 meses & $5,0 \mathrm{~g} / \mathrm{kg}$ & $2,035 \mathrm{~kg}$ & $19^{\circ} \mathrm{dia}$ & 14 dias & 33 dias & $\begin{array}{l}\text { Aborto Macho } \\
\text { (5738) }\end{array}$ \\
\hline $\begin{array}{l}\text { Vaca } \\
5739\end{array}$ & $\begin{array}{c}438 \\
\mathrm{~kg}\end{array}$ & - & - & - & $\begin{array}{l}\text { Início dos primeiros } \\
\text { sintomas após o aborto }\end{array}$ & & - & $\begin{array}{c}\text { Morreu } 43 \\
\text { dias após }\end{array}$ \\
\hline Intoxicação & & & & & foi de \pm 12 dias & & & o abortamento \\
\hline
\end{tabular}


Quadro 2. Cronologia e intensidade dos sinais clínicos (em dias após a ingestão da planta)

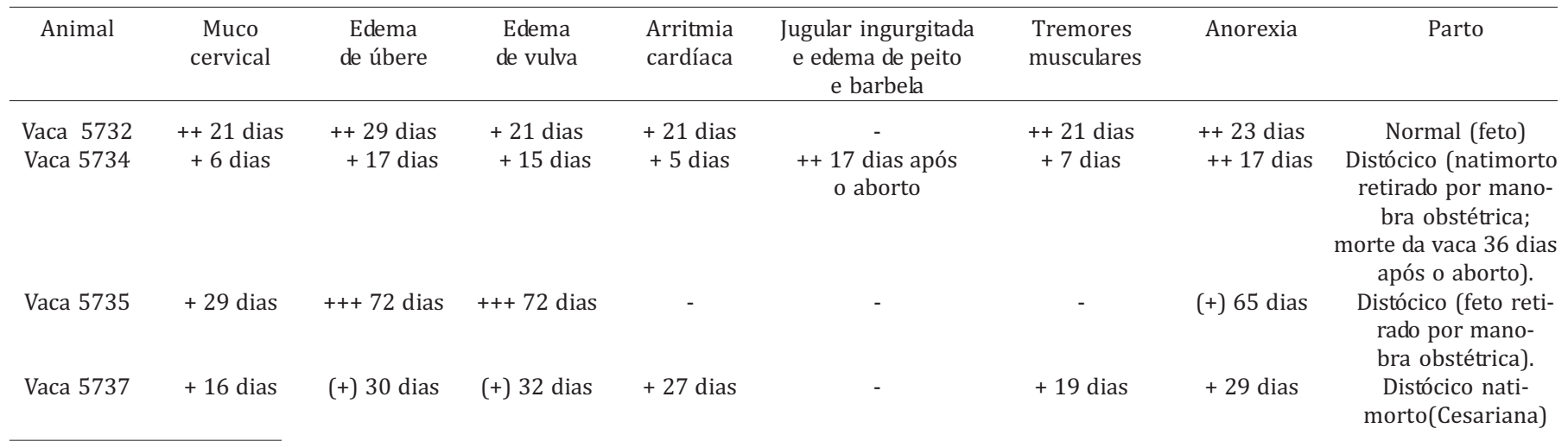

- Sinais clínicos ausentes, $(+)$ discretos, + leves, +(+) leves a moderados, ++ moderados, ++(+) moderados a acentuados, +++ acentuados.

Coqueiros, no distrito de Quirino, no mesmo município, verificamos grande quantidade de Tetrapterys multiglandulosa, bem como em diversas outras propriedades da região, porém o número de abortos relatados nesta fazenda era menor porque os pastos que continham a planta eram utilizados, sobretudo, para o pastejo de equinos e, raramente, para o gado; contudo, no período de 1995 a 2006, cinco vacas abortaram. Nesta propriedade, apesar da presença de éguas gestantes nas pastagens invadidas pela planta, não havia históricos de abortamento nessa espécie, nem da ingestão da planta por esses animais. No Sítio do Recreio, município de Rio das Flores, houve quatro abortos no período de 1999 a 2001. Segundo os históricos, todos os abortos ocorreram na fase final de gestação, isto é, entre o $7^{\circ}$ e 9 o meses.

\section{Dose e evolução clínica até o aborto}

Todas as vacas que receberam a planta $(2,5-10 \mathrm{~g} / \mathrm{kg} / \mathrm{dia})$ abortaram e uma delas morreu 36 dias após ter abortado $(10 \mathrm{~g} / \mathrm{kg} /$ dia $)$. 0 período da demonstração dos primeiros sintomas até o aborto, variou de 10 a 47 dias.

\section{Início dos sinais clínicos}

0 animal que recebeu a menor dose Vaca $5735(2,5 \mathrm{~g} / \mathrm{kg} /$ dia) apresentou os primeiros sinais clínicos 29 dias após o início de ingestão da planta. Nos bovinos que receberam dose de $5,0 \mathrm{~g} / \mathrm{kg} / \mathrm{dia}$, os primeiros sintomas foram observados 19

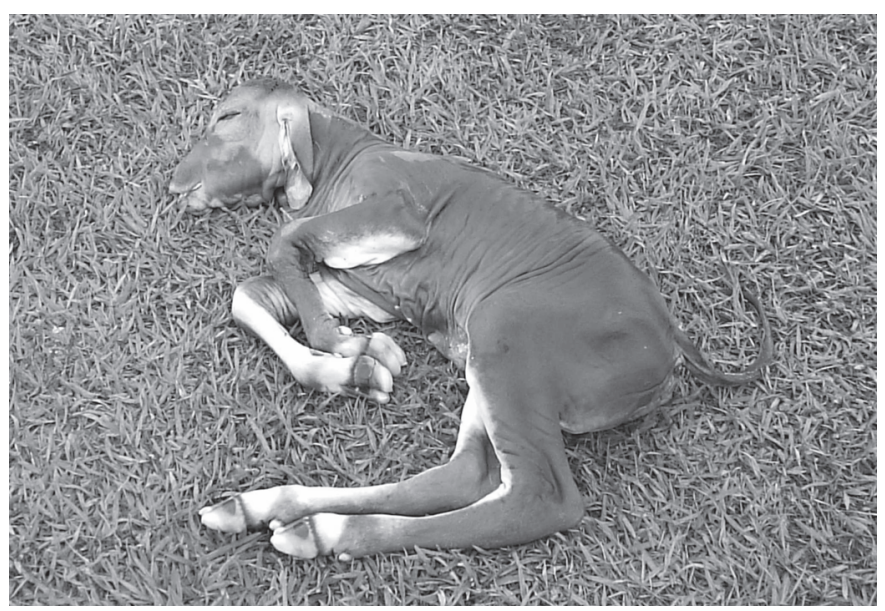

Fig.3. Feto 5731 abortado com dose de $5,0 \mathrm{~g} / \mathrm{kg} /$ dia de Tetrapterys acutifolia. e 21 dias (Vacas 5737 e 5732, respectivamente) após o início da administração da planta. No animal que recebeu a maior dose (Vaca 5734$)(10 \mathrm{~g} / \mathrm{kg} / \mathrm{dia})$, os sinais clínicos se iniciaram 5 dias após o começo da ingestão de Tetrapterys acutifolia.

\section{Quadro clínico geral}

Detalhes sobre o quadro clínico estão esquematizados no Quadro 2. Os abortos ocorreram entre o 8o e 9o mês de gestação (Fig.3). Todos os animais apresentaram aumento de liberação de muco cervical, edema de vulva e úbere e anorexia. 0 corrimento mucoso foi mais intenso nas duas semanas que antecederam o abortamento, já o edema de vulva e úbere foram mais acentuados 48 a 72 horas antes das vacas abortarem. A Vaca 5737 (5,0g/kg/dia) apresentou discreto edema de úbere e vulva e foi necessária a realização de cesariana devido à dilatação insuficiente da cérvix e vulva. 0 animal $5735(2,5 \mathrm{~g} / \mathrm{kg} / \mathrm{dia})$, que recebeu a menor dose, foi o único que não apresentou tremores musculares e arritmia cardíaca. Jugular ingurgitada e edema de peito e barbela (Fig.4) e arritmia cardíaca com ritmo de galope só foram observados na vaca que recebeu $10 \mathrm{~g} / \mathrm{kg} /$ dia e morreu 36 dias após o aborto. 0 animal 5735 demonstrou marcado aumento de volume abdominal, que normalizou após o parto, devido à liberação de 40 litros de líquido amniótico.

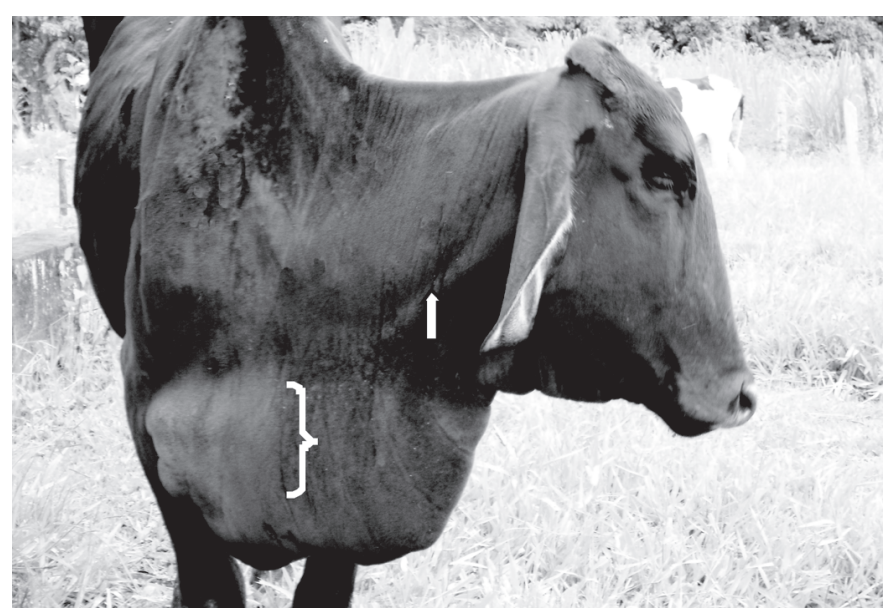

Fig.4. Veia jugular ingurgitada (seta), edema esternal e de barbela (chave), da Vaca 5734 intoxicada por Tetrapterys acutifolia $(10 \mathrm{~g} / \mathrm{kg} / \mathrm{dia})$. 
De todos os partos, apenas o da Vaca 5732 (5,0g/kg/dia) não foi distócico, mesmo assim com o nascimento de um bezerro morto (Feto 5731). No parto distócico da Vaca 5734 $(10 \mathrm{~g} / \mathrm{kg} / \mathrm{dia})$, apesar do bezerro apresentar as patas posicionadas corretamente, a cabeça encontrava-se desviada para trás e, após a manobra obstétrica, o bezerro (Natimorto 5733) foi retirado vivo, mas após 4 minutos morreu, depois de manifestar marcada arritmia cardíaca. Na Vaca 5735 (2,5g/ $\mathrm{kg} /$ dia), o feto também exibia a cabeça voltada para trás e uma pata deslocada para baixo e, após remoção, já encontrava-se morto (Feto 5736). No parto distócico da Vaca 5737 $(5,0 \mathrm{~g} / \mathrm{kg} / \mathrm{dia})$, foi necessária a realização de cesariana, dada à falta de dilatação da cérvix; o bezerro (Natimorto 5738) foi retirado com vida, mas nasceu fraco, não tentava se levantar, apresentava frequência respiratória normal, ligeira taquicardia, discreta arritmia e sobreviveu por apenas 10 horas.

A retenção de placenta foi uma complicação que ocorreu em todas as vacas e variou de 4 a 10 dias, mesmo após intenso tratamento com ocitocina nas primeiras 12 horas e cipionato de estradiol a cada dois dias.

No caso natural, a Vaca 5739 manifestou, 17 dias depois do aborto, arritmia cardíaca de galope, jugular ingurgitada, edema de peito e barbela, anorexia e morreu 43 dias após o abortamento.

\section{Achados de necropsia}

À necropsia, todos os fetos/natimortos apresentaram moderada quantidade de líquido sero-sanguinolento na cavidade torácica, abdominal e no saco pericárdico, além de leve a moderada quantidade de petéquias e equimoses no epicárdio e aurículas. Havia ainda discreta palidez na superfície de corte do miocárdio (Fig.5). Na região esternal do Feto 5736 e nas regiões submandibular e próximo a umbilical do Feto 5731, verificou-se leve a moderado edema no tecido subcutâneo. 0 fígado de dois fetos (Natimorto 5733 e Feto 5736) apresentava aspecto de noz-moscada (Fig.9).

O Feto 5731, que nasceu morto, encontrava-se muito autolisado e, portanto, os dados referentes ao exame histopatológico deste animal não foram considerados neste estudo.

0 Natimorto 5738 apresentou área de edema localmente extenso na região cortical do sistema nervoso central (substância branca) (Fig.8).

A Vaca 5734 apresentou acentuado edema na região esterno-abdominal, além de hidrotórax, ascite e hidropericárdio. Ao corte transversal do miocárdio, verificaram-se acentuadas áreas pálidas. As veias cava caudal e cranial e a aorta estavam dilatadas, assim como o ventrículo direito.

As lesões observadas na superfície de corte do miocárdio da Vaca 5739, intoxicada de forma natural, embora semelhantes, foram mais acentuadas e evidentes do que aquelas verificadas no coração do animal intoxicado experimentalmente.

\section{Achados histopatológicos}

No coração das vacas (caso experimental 5734 e natural 5739) os achados histológicos consistiam em alterações hemodinâmicas, degenerativo-necróticas, inflamatórias e proliferativas. Havia tumefação e vacuolização de fibras miocárdicas (Fig.7). As células tumefeitas evidenciavam variável aumento de volume, por vezes com halo claro em volta do núcleo, que mostrava-se vesiculoso, com a cromatina marginada e nucléolos evidentes. Havia ainda desorganização e afastamento dos miócitos. Em algumas áreas observavam-se espaços claros em meio às fibras tumefeitas, contendo detritos celulares, caracterizando lise celular. 0 edema intersticial estava presente entre as fibras e no interstício próximo a vasos sanguíneos. Observavam-se, nesse caso, finas linhas eosinofílicas interligando as miofibras afastadas (colágeno, Tricrômico de Masson positivo). Necrose incipiente e de áreas massivas também foi observada. Presença de fibras multinucleadas foi constante em locais onde os fenômenos degenerativo-necróticos eram mais acentuados. Observaram-se ainda miócitos "bizarros", isto é, aumentados de volume, grandes e disformes, com um ou vários núcleos aglomerados no seu centro. 0 infiltrado inflamatório era predominantemente mononuclear, constituído por linfócitos e macrófagos e localizava-se, principalmente, entre as miofibras e nas adjacências de vasos sanguíneos, nas áreas de edema intersticial e fibrose intersticial incipiente. A fibrose apresentava-se de duas maneiras: o primeiro tipo era mais comum e caracterizava-se por deposição intersticial difusa de colágeno por entre as fibras, isolando uma das outras. No segundo caso, apareciam grandes áreas de fibrose com variáveis quantidades de fibroblastos, que circundavam áreas de necrose massiva de miofibras. No miocárdio dos fetos havia edema intersticial com fibrose incipiente (Fig.6). Os achados microscópicos encontrados no coração encontram-se no Quadro 3.

No fígado das vacas havia congestão, que atingia as zonas centrais e, por vezes, parte da zona intermediária. Outra alteração frequente foi o edema do espaço de Disse, que na maioria das vezes restringia-se às áreas de congestão. A tumefação celular geralmente estava presente em locais onde havia congestão. Essa alteração caracterizava-se por hepatócitos aumentados de volume, com citoplasma granular ou espumoso, com núcleos muitas vezes vesiculosos. Vacuolização (mais frequente nas áreas congestas) era caracterizada por vacúolos de diversos tamanhos no citoplasma de hepatócitos, que por vezes mostravam sinais de comprometimento nuclear como picnose e cariorrexia. Em algumas áreas, células muito tumefeitas ou vacuolizadas evoluíam para lise. A fibrose aparecia principalmente na periferia e no centro dos lóbulos hepáticos e sob a cápsula. Nas zonas centrais permanecia apenas o arcabouço de estroma, no qual se depositava o colágeno. Nos espaços-porta, adicionalmente, observaram-se discreta fibrose e proliferação de ductos biliares. Nos fetos verificou-se apenas congestão hepática. (Fig.10)

No córtex das vacas e de três fetos (Fetos 5733, 5736 e 5738 ) havia espongiose (vacúolos grandes, redondos a ovais) e "microespongiose" em variáveis graus de intensidade (pequenos vacúolos) da camada profunda da substância cinzenta e da substância branca subcortical (Fig.11 e 12). Nas áreas com espongiose observou-se ainda edema astrocitário caracterizado por astrócitos com núcleos tumefeitos, vesiculares, com citoplasma pálido, inchado e limites celulares muitas vezes perceptíveis. Havia ainda necrose neuronal caracterizada por encarquilhamento e eosinofilia citoplasmáticas (neurônios vermelhos), picnose nuclear sem evidenciação 

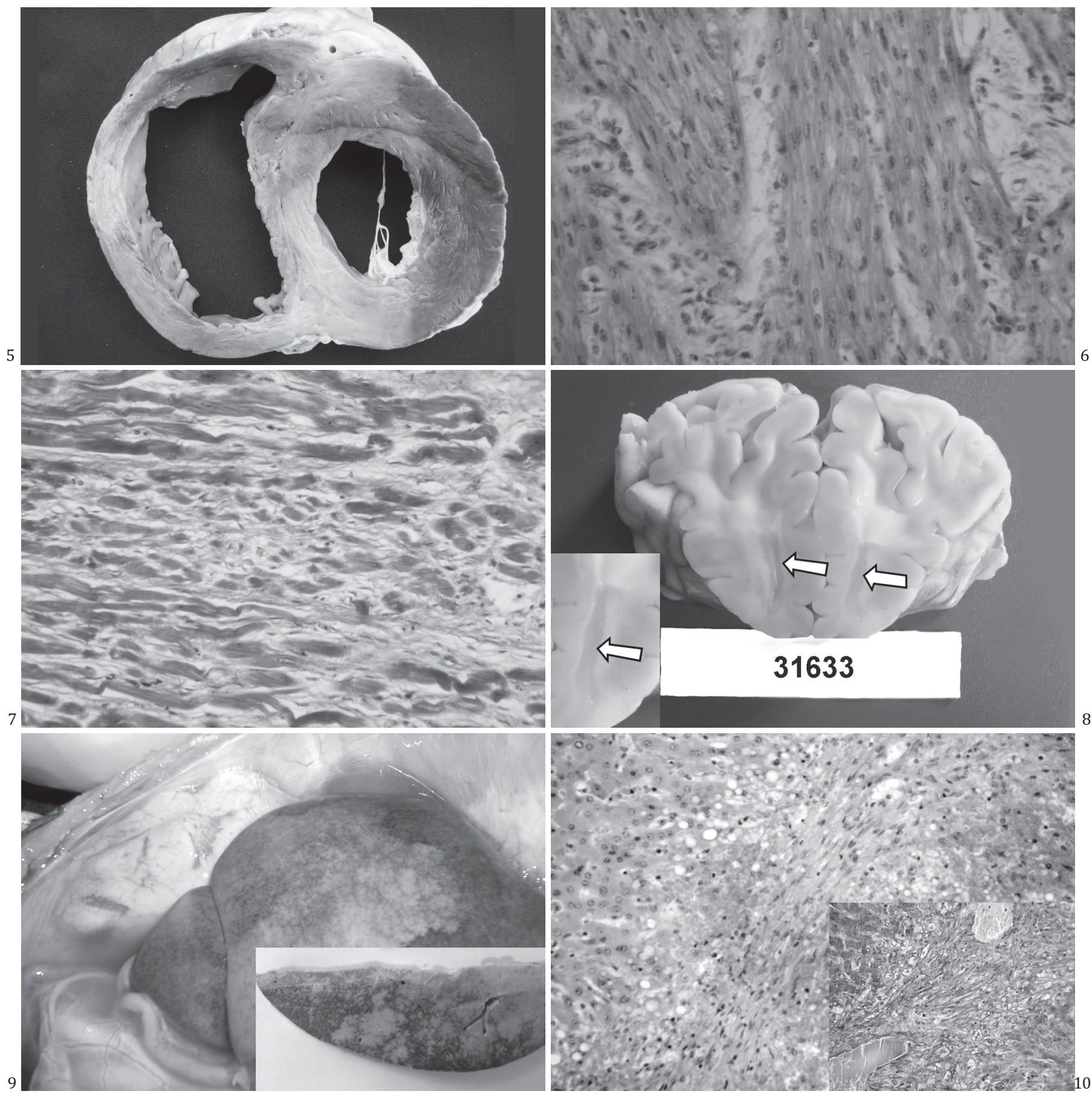

Fig.5. Áreas pálidas no miocárdio e dilatação bilateral na Vaca 5739 intoxicada naturalmente por Tetrapterys multiglandulosa.

Fig.7. Edema e fibrose intersticial por entre miócitos cardíacos, na Vaca 5734. Tricrômico de Masson, obj.16x e zoom de 1.7x.

Fig.9. Fígado com aspecto de noz-moscada do Natimorto $5733(10 \mathrm{~g} /$ $\mathrm{kg} /$ dia). No detalhe, superfície de corte do fígado após fixação em formol.

nucleolar e desaparecimento da substância de Nissl. Outros achados incluíram edema perivascular detectável pela presença de substância amorfa eosinofílica (glóbulos de proteína) no seu entorno. No córtex do Feto 5736 verificou-se marcada congestão. No bulbo havia hemorragia, necrose coagulativa

Fig.6. Leve edema e fibrose incipiente no miocárdio do Feto 5733. Tricrômico de Masson, obj.25x e zoom de 4.4x.

Fig.8. Edema subcortical (substância branca) do Natimorto 5738 $(5,0 \mathrm{~g} / \mathrm{kg} / \mathrm{dia})$, indicado pela seta.

Fig.10. Congestão, vacuolização (degeneração gordurosa), desaparecimento dos cordões de hepatócitos e área de fibrose na Vaca 5734. HE, obj.25x e zoom de 4.4x. No detalhe, desaparecimento dos hepatócitos e leve fibrose (azul) na Vaca 5739. Tricrômico de Masson, obj.25x.

neuronal, edema da neuropila, leve a moderada espongiose e "microespongiose" e em alguns neurônios observaram-se grânulos de Nissl ausentes ou rarefeitos e dispostos na periferia da célula (cromatólise de neurônios). No tálamo verificaram-se moderada a acentuada espongiose e 
Quadro 3. Achados histopatológicos observados no coração de vacas e fetos abortados após a intoxicação por Tetrapterys acutifolia

\begin{tabular}{|c|c|c|c|c|c|c|c|c|c|}
\hline $\begin{array}{l}\text { Bovino no. } \\
\text { (SAP) }\end{array}$ & $\begin{array}{l}\text { Tumefação } \\
\text { celular }\end{array}$ & $\begin{array}{c}\text { Edema } \\
\text { intersticial }\end{array}$ & Lise & $\begin{array}{c}\text { Necrose } \\
\text { incipiente }\end{array}$ & $\begin{array}{l}\text { Necrose } \\
\text { massiva }\end{array}$ & $\begin{array}{l}\text { Infiltrado inflama- } \\
\text { tório mononuclear }\end{array}$ & $\begin{array}{l}\text { Miócitos } \\
\text { bizzaros }\end{array}$ & $\begin{array}{c}\text { Fibrose } \\
\text { intersticial }\end{array}$ & $\begin{array}{c}\text { Extensas áreas } \\
\text { de fibrose }\end{array}$ \\
\hline $\begin{array}{c}\text { Natimorto } \\
5733(31150)\end{array}$ & - & + & - & - & - & + & - & + & - \\
\hline $\begin{array}{c}\text { Feto } 5736 \\
(31449)\end{array}$ & - & + & - & - & - & - & - & + & - \\
\hline $\begin{array}{c}\text { Natimorto } \\
5738(31633)\end{array}$ & - & + & - & - & - & $(+)$ & - & + & - \\
\hline $\begin{array}{c}\text { Vaca } 5734 \text { - caso } \\
\text { experimental } \\
(31196)\end{array}$ & + & ++ & ++ & + & + & $+(+)$ & ++ & ++ & +++ \\
\hline $\begin{array}{c}\text { Vaca } 5739 \text { - caso } \\
\text { natural } \\
(31649)\end{array}$ & + & ++ & + & + & + & $+(+)$ & ++ & $++(+)$ & ++ \\
\hline
\end{tabular}

- Ausente, (+) discreto, + leve, $+(+)$ leve - moderado, ++ moderado, ++(+) moderado - acentuado, +++ acentuado.

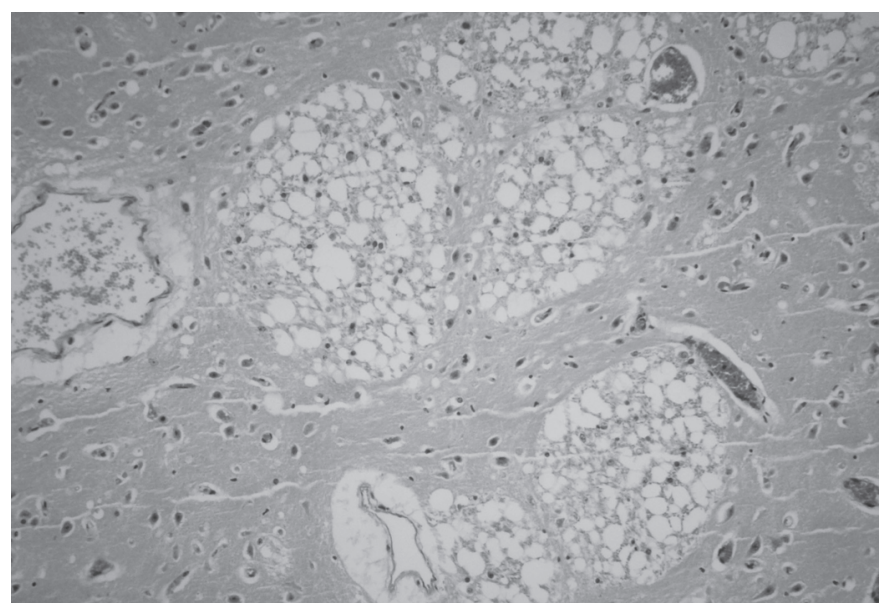

Fig.11. Acentuado edema dos tratos nervosos da substância branca subcortical do Feto 5736 (2,5g/kg/dia). Obj.10x e zoom de 3.3x.

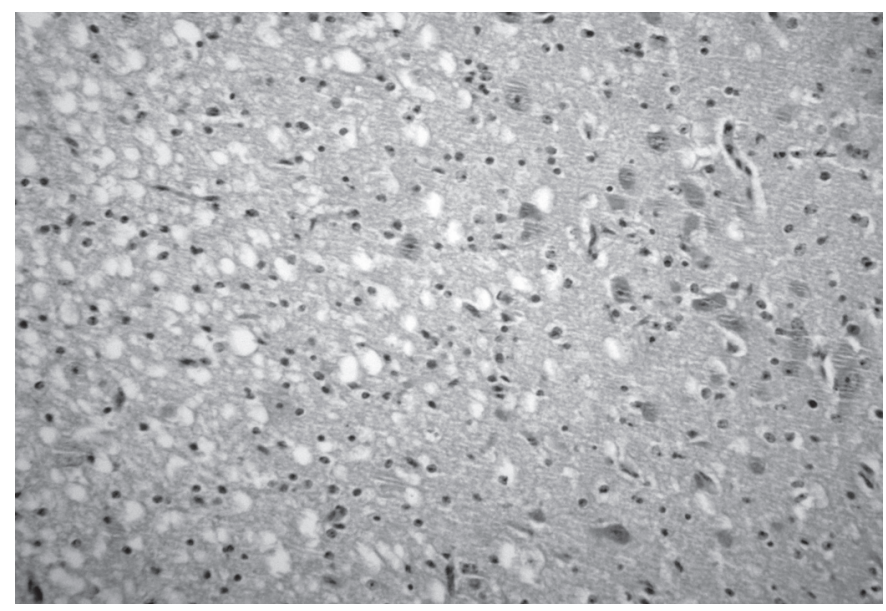

Fig.12. Vacuolização (espongiose) na interface entre as substâncias branca e cinzenta subcorticais no Natimorto 5738 . Obj.25x e zoom de 1.7x.

"mIicroespongiose", necrose coagulativa com lise de neurônios, gliose, cromatólise e, ocasionalmente eram observados grupos de dois ou três astrócitos com núcleos vesiculosos e tumefeitos, morfologia compatível com astrócitos Alzheimer tipo II, edemas perivascular e astrocitário. No mesencéfalo havia leve a moderada espongiose e "microespongiose", além de edema perivascular e tumefação de astrócito. No cerebelo observou-se espongiose na substância branca. Na medula cervical havia leve espongiose na substância branca e cromatólise de alguns neurônios. Nas áreas com espongiose, observou-se edema astrocitário. Não foram observadas alterações histológicas na placenta das vacas.

\section{DISCUSSÃO}

Através de experimentação, comprovou-se que a ingestão de Tetrapterys acutifolia tem efeito abortivo para bovinos, além de induzir o quadro da forma nervosa da enfermidade, caracterizada clinicamente por letargia e depressão, em todos os bovinos. Adicionalmente, verificaram-se em uma das quatro vacas do grupo experimental e em outra intoxicada de forma natural, sinais clínicos típicos de insuficiência cardíaca. 0 quadro clínico-patológico verificado nas vacas foi semelhante ao descrito em bovinos (Tokarnia et al. 1989, Carvalho et al. 2006) e ovinos (Riet-Correa et al. 2005) intoxicados por Tetrapterys spp., bem como ao descrito em bovinos (Gava 1993, Stolf et al. 1994) e ovinos (Raffi et al. 2004) intoxicados por Ateleia glazioviana. É provável que o bovino intoxicado de forma natural (Vaca 5739) tenha ingerido cerca de $10 \mathrm{~g} / \mathrm{kg}$ da planta, uma vez que o quadro clínico patológico foi similar ao observado na Vaca 5734, intoxicada experimentalmente com esta dose.

É possível que a maior gravidade das lesões (palidês) cardíaca verificada no caso natural, quando comparada com à observada no animal experimental, possa ser resultado do exercício físico mais intenso em casos de intoxicação natural, como acredita Gava (2001), uma vez que os animais permanecem soltos no pasto e não confinados em baias, o que propicia o desenvolvimento de marcada fibrose cardíaca, como foi observado em casos de Ateleia glazioviana.

Embora seja evidente que a morte dos animais adultos intoxicados por Tetrapterys spp. é determinada por insuficiência do coração, a patogênese das lesões cardíacas, tanto em adultos quanto nos fetos, permanece desconhecida. Pensamos inicialmente que as lesões primárias seriam de natureza degenerativo-necrótica, após as quais se desencadeariam fenômenos proliferativos reacionais (fibroblastos e colágeno). Porém, é possível, como sugerem Barros \& Peixoto (2009), que as lesões degenerativo-necróticas (grandes áreas de ne- 
crose coagulativa e necrose de miócitos isolados) possam ser secundárias à isquemia determinada pela dificuldade de irrigação e oxigenação vascular associadas à retração cicatricial, por sua vez causada pela marcada fibrose intersticial (aspecto que predomina no quadro histológico). De fato, apenas 2 de 14 bovinos adultos intoxicados naturalmente por Tetrapterys spp. evidenciaram grandes áreas de necrose coagulativa no miocárdio, enquanto 13 de 14 bovinos evidenciaram fibrose intersticial. Achados similares, embora menos evidentes, também foram verificados em fetos abortados de vacas intoxicadas de forma natural por Tetrapterys spp., nos quais observaram-se necrose do miocárdio em 3 de 6 fetos e fibrose intersticial em quase todos os casos examinados $(5 / 6)$ (Tokarnia et al. 1989). A fibrose intersticial, por seu turno, poderia estar associada ao edema intersticial, isto é, a proliferação de tecido conjuntivo e deposição de colágeno podem ser consequentes à presença de proteínas séricas no interstício, como sugere Jones \& Hunt (1983).

Ao que parece, a causa da morte dos fetos abortados é a mesma dos animais adultos que ingerem a planta, isto é, insuficiência cardíaca causada por dano direto do princípio tóxico da planta ao miocárdio que, no caso do feto, atravessa a barreira placentária. Evidências macroscópicas e histopatológicas de insuficiência cardíaca no feto e ausência de lesões placentárias observadas nos animais deste estudo, bem como em ovinos intoxicados por Ateleia glazioviana (Raffi et al. 2004) e caprinos intoxicados por Tetrapterys multiglandulosa (Cardinal et al. 2010) reforçam essa hipótese. Por outro lado, é difícil precisar até que ponto as lesões no SNC dos fetos contribuem para o óbito. Esses resultados diferem dos descritos em caprinos intoxicados experimentalmente por $T$. multiglandulosa (Melo et al. 2001), que atribuem os abortos às lesões placentárias. Acredita-se, ainda, que a patogênese dos abortos causados por T. multiglandulosa e A. glazioviana seja a mesma (Carvalho et al. 2006), e que o princípio ativo dessas plantas seja similar (Riet-Correa et al. 2005). Os achados necroscópicos encontrados no coração dos fetos deste estudo foram semelhantes aos descritos nas intoxicações naturais por Tetrapterys spp. no município de Valença-RJ (Caldas et al. 2005).

Quadro histológico semelhante tem sido descrito no coração de ratos estimulados cronicamente por isoproterenol, um fármaco derivado da noradrenalina e potente agonista $\beta$ adrenérgico (Westfall \& Westfall 2006) que induz à hipertrofia cardíaca (Zierhut \& Zimmer 1989), fibrose miocárdica e disfunção progressiva e por fim, insuficiência cardíaca (Shubeita et al. 1992). Nesses casos também são observadas células gigantes, a exemplo do descrito por Tokarnia et al. (1989) em bovinos intoxicados por Tetrapterys spp.; esses autores as denominaram de células gigantes miogênicas e as interpretaram como tentativas infrutíferas de regeneração do miocárdio. A patogênese exata da lesão cardíaca provocada pelo isoproterenol, entretanto, também ainda não está totalmente esclarecida (Grimm et al. 1998). Alguns autores são da opinião que, nesses casos, a acentuada proliferação do colágeno em animais que desenvolvem hipertrofia miocárdica resulte de processos reparativos à necrose muscular isquêmica induzida pela droga (Lin 1973, Tang \& Taylor 1996) em decorrência do aumento abrupto e intenso do trabalho cardíaco sem o necessário aporte de oxigênio através da circulação coronariana (Grimm et al. 1998).

A intoxicação por Tetrapterys spp. em bovinos e ovinos pode ser comparada, em diversos aspectos, à intoxicação causada por várias espécies de rubiáceas (Pachystigma pygmaeum, P. thamnus, P. latifolium, Pavetta harborii, P. schumannian e Fadogia homblei, conhecida também como $F$. monticola) que ocorrem na África do Sul (Hunter et al. 1972, Kellerman et al. 1988, Fourie et al. 1989) e causam a chamada "gousiekte", doença de bovinos intoxicados por plantas que contêm pavetamina (Schultz et al. 2004). De fato, a observação mais cuidadosa evidencia que as graves lesões cardíacas de natureza regressivo-proliferativa encontradas na "gousiekte" (=doença rápida) guardam semelhança com as descritas na intoxicação por Tetrapterys spp. Além disso, para produzir tais lesões cardíacas em bovinos, essas plantas também têm que ser ingeridas em grandes quantidades, durante períodos prolongados. Porém, a rara influência do exercício, bem como a evolução clínica subaguda a crônica na intoxicação por Tetrapterys spp. diferem do quadro determinado pelas plantas africanas que, em geral, levam à morte de maneira superaguda (insuficiência cardíaca aguda e morte súbita), especialmente quando os animais são movimentados e, com menor frequência, por insuficiência cardíaca congestiva crônica. Além disso, as plantas africanas aparentemente não causam aborto, nem determinam lesões no sistema nervoso central (status spongiosus) como descrito em bovinos e ovinos intoxicados por Tetrapterys spp. e A. glazioviana (Tokarnia et al. 1989, Gava \& Barros 2001, Gava et al. 2001, Stigger et al. 2001). Outra semelhança presente nos quadros clínicos de intoxicação pelas plantas que causam "gousiekte" e por T. multiglandulosa foi recentemente descrita por Carvalho et al. (2006), que verificaram sinais clínicos e lesões cardíacas em bovinos removidos há dois meses do pasto onde havia a planta. Estudos experimentais realizados em ovinos intoxicados por T. multiglandulosa também sugerem que há um período de latência entre a ingestão da planta e o desenvolvimento das lesões cardíacas (Riet-Correa et al. 2005). Tal período de latência (4 a 8 semanas após a ingestão da planta) é uma característica da intoxicação pelas plantas africanas (Hunter et al. 1972, Kellerman et al. 1988, Fourie et al. 1989).

Neste estudo todas as vacas intoxicadas experimentalmente por Tetrapterys acutifolia manifestaram sinais clínicos de origem nervosa (letargia e depressão), cuja intensidade variou diretamente em função da gravidade dos sinais clínicos. Esse quadro nervoso tem sido relacionado à espongiose (status spongiosus) do sistema nervoso central causada pela planta, o que de fato, pôde ser evidenciado no exame histopatológico das vacas que morreram, bem como no encéfalo dos fetos abortados. Tal lesão foi semelhante à descrita, inicialmente, por Tokarnia et al. (1989) em bovinos intoxicados por Tetrapterys spp. que exibiam sinais clínicos de insuficiência cardíaca, e mais tarde também em ovinos intoxicados por $T$. multiglandulosa (Riet-Correa et al. 2005, Carvalho et al. 2006, Cardinal et al. 2010), bem como aquela demonstrada em bovinos e ovinos, que manifestam uma síndrome letárgica, após a ingestão de altas doses de Ateleia glazioviana (Gava \& Barros 2001, Gava et al. 2001, Stigger et al. 2001, Raffi et al. 2004, 2006). Estudos recentes por microscopia eletrônica compro- 
varam que a espongiose do sistema nervoso é causada por edema intramielínico (Riet-Correa et al. 2005), semelhante ao que ocorre na intoxicação por A. glazioviana (Raffi et al. 2006).

Essa lesão é histologicamente semelhante à observada na encefalopatia hepática; na doença hereditária dos bovinos conhecida como doença da urina do xarope de bordo (Baird et al. 1987) e nas intoxicações por Helychrysum spp., Stypandra glauca (McAuliffe \& Whiter 1976, Van der Lugt et al. 1996), closantel (Gill et al. 1999) e na neuromicotoxicose causada por Diplodia maydis (=Sternorcapella maydis) (Kellerman et al. 1991). Contudo, aparentemente, as lesões espongióticas no SNC não guardam correlação com a estase crônica no fígado, mesmo porque as lesões hepáticas não são graves o suficiente. Nos animais intoxicados por Helychrysum spp., Stypandra glauca e closantel (Basson et al. 1975, McAuliffe \& White 1976, Van der Lugt et al. 1996, Ecco et al. 1999, Gill et al. 1999, Van der Lugt \& Venter 2002, Van der Lugt et al. 2002,) a espongiose da substância branca é reversível, exceto no nervo ótico que apresenta lesões irreversíveis devido à compressão, necrose e fibrose da porção intra-óssea do nervo dentro do canal óptico.

Até o momento não foram publicados experimentos com Tetrapterys spp. em animais de laboratório, no entanto, a administração de A. glazioviana (que aparentemente possui principio tóxico similar) a ratos, camundongos, cobaios e coelhos não foi capaz de reproduzir a doença (Leite et al. 2002).

Algumas considerações devem ser feitas em relação ao diagnóstico diferencial. Outras enfermidades que cursam com aborto tais como, brucelose, diarréia viral bovina (BVD), rinotraqueíte infecciosa bovina (IBR), leptospirose, campilobacteriose e tricomonose devem ser diferenciadas do abortamento causado pela intoxicação por Tetrapterys spp. Cabe ressaltar que neste estudo foram realizados exames ginecológicos e sorológicos, os quais resultaram negativos, o que permitiu descartar o envolvimento de tais agentes na patogênese do aborto. Além disso, em casos de brucelose, apesar do aborto ocorrer principalmente nos últimos três meses de gestação, o exame macroscópico revela lesões placentárias que se caracterizam por necrose de cotilédones e edema na área intercotiledonária (Radostits et al. 2002, Antoniassi et al. 2007, Riet-Correa 2007). É interessante lembrar que, em casos de campilobacteriose, apesar dos abortos ocorrerem em qualquer período de gestação, sobretudo, em torno de 4-6 meses, macroscopicamente, as lesões placentárias são semelhantes àquelas encontradas na brucelose (necrose e autólise) (Fernades 2001, Vanzin 2008). Por outro lado, em casos de tricomonose, o aborto é comum por volta dos 5 meses de gestação e os fetos abortados não apresentam alterações macroscópicas (Pellegrin \& Leite 2003). Já em casos de aborto por IBR, o vírus pode provocar infecção primária restrita ao trato respiratório, olhos e trato reprodutivo da vaca e o abortamento ocorre, normalmente, algumas semanas após a doença clinica ou à vacinação (na maioria dos casos, na segunda metade de gestação, isto é, entre o $5^{\circ}$ a $8^{\circ}$ meses); os fetos abortados apresentam autólise moderada e hepatite necrosante focal e não há retenção de placenta (Kirkbride 1992, Fernandes 2001, Radostits et al. 2002). No caso do aborto por BVD, as lesões verificadas no feto ainda não estão muito bem estabelecidas e seu valor diagnóstico ainda é controverso; adicionalmente osteopetrose pode ser observada nos fetos (Radostits et al. 2002); nesses casos, o aborto pode ocorrer até os 4 meses de gestação (Ferreira de sá, 1991). Em casos de leptospirose, os abortos ocorrem a partir do $6^{\underline{0}}$ mês de gestação e, em geral, não são evidenciadas lesões macroscópicas nos fetos, todavia, microscopicamente pode ser observada necrose tubular e nefrite intersticial em alguns fetos (Fernandes 2001, Radostits et al. 2002, Antoniassi et al. 2007).

Embora a intoxicação por Ateleia glazioviana seja semelhante, em diversos aspectos, à intoxicação por Tetrapterys spp. (Tokarnia et al. 2000), tais plantas possuem distribuição distinta no país e, portanto, os dados epidemiológicos são suficientes para diferenciá-las. Clinicamente, outras enfermidades que cursam com insuficiência cardíaca como a reticulopericardite traumática, leucose e endocardites valvulares (Radostits et al. 1995) podem ser confundidas com a intoxicação por Tetrapterys spp., mas, em geral, tais doenças ocorrem sob a forma de casos isolados no rebanho e os achados macroscópicos são característicos, o que possibilita o diagnóstico definitivo.

Em relação às alterações macroscópicas evidenciadas no coração de bovinos intoxicados por Tetrapterys spp., devem ser descartadas outras enfermidades que cursam com lesões similares, tais como a intoxicação por sementes de Cassia occidentalis, deficiência de selênio e vitamina $\mathrm{E}$, bem como a intoxicação por antibióticos ionóforos (Tokarnia et al. 2000). Essas enfermidades, porém, cursam com lesões na musculatura esquelética e, em menor escala no coração. No caso da deficiência de selênio e vitamina $E$, a necrose de coagulação das fibras musculares frequentemente cursa com mineralização; enquanto que, em casos de intoxicação por antibióticos ionóforos, há fraqueza muscular e diarréia (Nogueira et al. 2009).

Agradecimentos.- À Professora Dra. Vera Lúcia Teixeira de Jesus pela realização dos exames das doenças da esfera reprodutiva, realizados no Setor de Reprodução Animal da UFRRJ e também na Fundação de Estudo e Pesquisa em Medicina Veterinária e Zootecnia (FEP-MVZ), Coordenação Preventiva da UFMG; e à CAPES pela concessão de bolsa de doutorado.

\section{REFERÊNCIAS}

Almeida M.B., Priebe A.P.S., Riet-Correa B., Riet Correa G., Fiss L., Raffi M.B. \& Schild A.L. 2008. Evolução da reversibilidade das lesões neurológicas e cardíacas em ovinos intoxicados experimentalmente por Ateleia glazioviana e Tetrapterys multiglandulosa. Pesq. Vet. Bras. 28(3):129-134.

Antoniassi N.A.B., Santos A.S., Oliveira E.C., Pescador C.A. \& Driemeier D. 2007. Diagnóstico das causas infecciosas de aborto em bovinos. Biologico, S. Paulo, 69(2):69-72.

Baird J.D., Wojcinski Z.W., Wise A.P. \& Godkin M.A. 1987. Maple syrup urine disease in five hereford calves in Ontario. Can. Vet. J. 28(8):505-511.

Barros C.S.L. \& Peixoto P.V. 2009. Comunicação pessoal (Depto Patologia, UFSM, Santa Maria, RS, e Depto Nutrição Animal e Pastagem, UFRRJ, Seropédica, $\mathrm{RJ}$ ).

Basson P.A., Kellerman T.S., Albl P., Maltitz L.J.F., Miller E.S. von \& Welman W.G. 1975. Blindness and encephalopathy caused by Helichrysum argyrosphaerum D.C. (Compositae) in sheep and cattle. Onderstepoort J. Vet. Res. 42(4):135-148.

Caldas S.A., Gabriel A.M.A., Amorim A. \& Conceição J.H.S. 2005. Intoxicação de bovinos por plantas no médio Paraíba, RJ. Revta Bras. Med. Vet. 27(2):27-30.

Cardinal S.G., Aniz A.C., Santos B.S., Carvalho N.M. \& Lemos R.A.A. 2010. 
Lesões perinatais em cordeiros induzidas pela administração de Tetrapterys multiglandulosa (Malpighiaceae) a ovelhas em diferentes estágios de gestação. Pesq. Vet. Bras. 30(1):73-78.

Carvalho N.M., Alonso L.A., Cunha T.G., Ravedutti J., Barros C.S.L. \& Lemos R.A.A. 2006. Intoxicação de bovinos por Tetraperys multiglandulosa (Malpighiaceae) em Mato Grosso do Sul. Pesq. Vet. Bras. 26(3):139-146.

Ecco R., Gava A., Graça D.L. \& Barros C.S.L. 1999. Intoxicação por closantel em caprinos: relato de caso. Anais 9o Encontro Nacional de Patologia Veterinária, Belo Horizonte, p.91. (Resumo)

Fernandes C.G. 2001. Doenças da reprodução: abortos em bovinos. In: RietCorrea F., Mendez M.C. \& Schild A.L.F. (Eds), Doenças em Ruminantes e Eqüinos. 2a ed. Varela, São Paulo, p.349-361.

Ferreira de Sá W. 1991. Abortamento em bovinos. Documento 49, Embrapa Gado de Leite, Coronel Pacheco, MG.

Fourie N., Schultz R.A., Prozesky L., Kellerman T.S. \& Labuschagne L. 1989. Clinical pathological changes in gousiekte, a plant-induced cardiotoxicosis of ruminants. Onderstepoort J. Vet. Res. 56:73-80.

Gava A. 1993. Intoxicação por Ateleia glazioviana. In: Riet-Correa F., Mendez M.C., Schild A.L. (Eds), Intoxicações por Plantas Tóxicas e Micotoxicoses em Animais Domésticos. Editorial Agropecuária, Hemisfério Sur, Montevideo, p.222-225.

Gava A. 2001. Comunicação pessoal (Universidade de Desenvolvimento do Estado de Santa Catarina, Lages, SC).

Gava A. \& Barros C.S.L. 2001. Field observations of Ateleia glazioviana poisoning in cattle in southern Brazil. Vet. Human Toxicol. 43:37-41.

Gava A., Barros C.S.L., Pilati C., Barros S.S. \& Mori A.M. 2001. Intoxicação por Ateleia glazioviana (Leg. Papilionoideae) em bovinos. Pesq. Vet. Bras. 21:49-59.

Gill P.A., Cook R.W., Boulton J.G., Kelly W.R., Vanselow B. \& Reddacliff L.A. 1999. Optical neuropathy and retinopathy in closantel toxicosis of sheep and goats. Aust. Vet. J. 77(4):259-261.

Grimm D., Elsner D., Schunkert H., Pfeifer M., Griese D., Bruckschlegel G., Muders F., Riegger G.A. \& Kromer E.P. 1998. Development of heart failure following isoproterenol administration in the rat: Role of the reninangiotensin system. Cardiovasc. Res. 37:91-100.

Hunter L.R., Naudé T.W., Adelaar T.F., Smit J.D. \& Codd L.E. 1972. Ingestion of the plant Fadogia monticula Robins as an additional cause of gousiekte in ruminants. Onderstepoort J. Vet. Res. 39(1):71-83.

Jones T.C. \& Hunt R.D. 1983. Veterinary Pathology. $5^{\text {th }}$ ed. Lea and Febiger, Philadelphia.

Kellerman T.S., Coetzer J.A. \& Naudé T.W. 1988. Plant Poisonings and Mycotoxicoses of Livestock in Southern Africa. Oxford University Press, Cape Town, p.83-130.

Kellerman T.S., Prozesky L., Schultz R. Anitra, Rabie C.J., Van Ark H., Maartens B.P. \& Lübben A. 1991. Perinatal mortality in lambs of ewes exposed to cultures of Diplodia maydis (=Sternorcapella maydis) during gestation. Onderstepoort J. Vet. Res. 58:297-308.

Kirkbride C.A. 1992. Viral agents and associated lesions detected in a 10year study of bovine abortions and stillbirths. J. Vet. Diagn. Invest. 4:374379.

Leite L.G., Riet-Correa F., Medeiros R.M.T., Piacenti A., Aragão M. \& Schons S.V. 2002. Susceptibilidade de animais de laboratório à intoxicação por Ateleia glazioviana (Leg. Papilionoideae). Pesq. Vet. Bras. 22:73-78.

Lin Y.C. 1973. Hemodynamics in the rat with isoproterenol induced cardiac hypertrophy. Res Commun. Chem. Pathol. Pharmacol. (6):213-220.

Melo M.M., Vasconcelos A.C., Dantas G.C., Serakides R. \& Alzamora Filho F. 2001. Experimental intoxication of pregnant goats with Tetrapterys multiglandulosa A.Juss. (Malpighiaceae). Arq. Bras. Med. Vet. Zootec. 53:58-65.

McAuliffe P.R. \& White W.E. 1976. “Woolly everlasting daisy” (Helichrysum blandoskianum) toxicity in cattle and sheep. Aust. Vet. J. 52:366-368.

Nogueira V.A., França T.N. \& Peixoto P.V. 2009. Intoxicação por antibióticos ionóforos em animais. Pesq. Vet. Bras. 29:(3):191-197.
Pellegrin A.O. \& Leite R.C. 2003. Atualização sobre tricomonose genital bovina. Documento 54, Embrapa Pantanal, Corumbá. (Formato digital)

Radostits M., Blood D.C. \& Gay C.C. 1995. Veterinary Medicine. $8^{\text {th }}$ ed. Baillière Tindall, London. 1763p.

Radostits O.M., Blood D.C. \& Gay C.C. 2002. Clínica Veterinária: um tratado de doenças dos bovinos, ovinos, suínos, caprinos e eqüinos. $9^{\text {th }}$ ed. Guanabara Koogan, Rio de Janeiro. 1737p.

Raffi M.B., Barros R.R., Bragança J.F.M., Rech R.R., Oliveira F.N. \& Barros C.S.L. 2004. The pathogenesis of reproductive failure induced in sheep by the ingestion of Ateleia glazioviana. Vet. Hum. Toxicol. 46:233-238.

Raffi M.B., Rech R.R., Sallis E.S.V., Rodrigues A. \& Barros C.S.L. 2006. Chronic cardiomyopathy and encephalic spongy changes in sheep experimentally fed Ateleia glazioviana. Ciência Rural 36(6):1860-1866.

Riet-Correa F. 2007. Doenças víricas, p.169-173. In: Riet-Correa F., Schild A.L., Lemos R.A.A. \& Borges J.R.J. (Eds), Doenças de Ruminantes e Equideos. $3^{3}$ ed. Pallotti, Santa Maria.

Riet-Correa G., Terra F.F., Schild A.L., Riet-Correa F. \& Barros S.S. 2005. Intoxicação experimental por Tetrapterys multiglandulosa (Malpighiacea) em ovinos. Pesq. Vet. Bras. 25:91-96.

Schultz R.A., Fourie N., Bode M.L., Basson K.M., Labuschagne L., Snyman L.D. \& Prozesky L. 2004. Pavetamine: An inhibitor of protein synthesis in the heart, p.408-411. In: Acamovic T., Stewart C.S. \& Pennycott T.W. (Eds), Poisonous Plants and Related Toxins. CABI Publishing, Wallingford, UK.

Shubeita H.E., Martinson E.A., Van Bilsen M., Chien K.R. \& Brow J.H. 1992. Transcriptional activation of the cardiac myosin light chain 2 and atrial natriuretic factor genes by protein kinase $\mathrm{C}$ in neonatal rat ventricular myocytes. Proc. Natl Acad. Sci. USA. 89:1305-1309.

Stigger A.L., Barros C.S.L., Langohr I.M. \& Barros S.S. 2001. Intoxicação experimental por Ateleia glazioviana (Leg. Papilionoideae) em ovinos. Pesq. Vet. Bras. 21:98-108.

Stolf L., Gava A., Varaschin M.S., Neves D.S., Mondadori A.J. \& Scolari L.S. 1994. Aborto em bovinos causado pela ingestão de Ateleia glazioviana (Leg. Papilionoideae). Pesq. Vet. Bras. 14:15-18.

Tang Q. \& Taylor P.B. 1996. Altered contractile function in isoproterenolinduced hypertrophied rat heart. J. Hypert. (14):751-757.

Tokarnia C.H., Peixoto P.V., Döbereiner J., Consorte I.B. \& Gava A. 1989. Tetrapterys spp. (Malpighiaceae): a causa de mortandades em bovinos caracterizadas por alterações cardíacas. Pesq. Vet. Bras. 9:23-44.

Tokarnia C.H., Döbereiner J. \& Peixoto P.V. 2000. Plantas Tóxicas do Brasil. Editora Helianthus, Rio de Janeiro, p.19-61.

Van der Lugt J.J. 2002. Myelinopathies, p.67. In: Van der Lugt J.J. (Ed.), The Clinicopathology and Pathology of Selective Toxicoses and Storage Diseases of the Nervous System of Ruminants in Southern Africa. PhD Thesis, University of Utrecht, The Netherlands. 174p.

Van der Lugt J.J., Olivier J. \& Jordaan P. 1996. Status spongiosus, optic neuropathy and retinal degeneration in Helichrysum argyrosphaerum poisoning in sheep and a goat. Vet. Pathol. 33:495-502.

Van der Lugt J.J. \& Venter I. 2002. Myelin vacuolation, optic neuropathy and retinal degeneration following closantel overdosage in sheep and a goat, p.83-97. In: Van der Lugt J.J. (Ed.), The Clinicopathology and Pathology of Selective Toxicoses and Storage Diseases of the Nervous System of Ruminants in Southern Africa. Tese de Doutorado, University of Utrecht, The Netherlands. 174p.

Vanzin I.M. 2008. Principais enfermidades de interesse reprodutivo. Disponível em <http://www.inseminacaoartificial.com.br/Principais_ enfermidades.htm> Acesso em 22 abr.

Westfall T. \& Westfall D. 2006. Adrenergic agonists and antagonists, p.237296. In: Goodman L.S., Gilman A., Brunton L.L. Lazo J.S. \& Parker K.L. (Eds), Goodman \& Gilman's The Pharmacological Basis of Therapeutics. $11^{\text {th }}$ ed. McGraw-Hill, New York.

Zierhut W. \& Zimmer H.G. 1989. Triiodothyronine-induced changes in function, metabolism and weight of the rat heart: Effects of $\alpha$ - and $\beta$ adrenergic blockade. Basic Res. Cardiol. 84:359-70. 